\title{
Pericellular activation of hepatocyte growth factor by the transmembrane serine proteases matriptase and hepsin, but not by the membrane-associated protease UPA
}

\author{
Kate A. OWEN*, Deyi QIU*, Juliano ALVES $\dagger$, Andrew M. SCHUMACHER $\dagger$, Lynette M. KILPATRICK*, Jun LI†, Jennifer L. HARRIS $†$ \\ and Vincent ELLIS*1 \\ *Biomedical Research Centre, School of Biological Sciences, University of East Anglia, Norwich NR4 7TJ, U.K., and †Genomics Institute of the Novartis Research Foundation, 10675 \\ John Jay Hopkins Drive, San Diego, CA 92121, U.S.A.
}

\begin{abstract}
HGF (hepatocyte growth factor) is a pleiotropic cytokine homologous to the serine protease zymogen plasminogen that requires canonical proteolytic cleavage to gain functional activity. The activating proteases are key components of its regulation, but controversy surrounds their identity. Using quantitative analysis we found no evidence for activation by uPA (urokinase plasminogen activator), despite reports that this is a principal activator of pro-HGF. This was unaffected by a wide range of experimental conditions, including the use of various molecular forms of both $\mathrm{HGF}$ and $\mathrm{uPA}$, and the presence of uPAR (uPA receptor) or heparin. In contrast the catalytic domains of the TTSPs (type-II transmembrane serine proteases) matriptase and hepsin were highly efficient activators (50\% activation at 0.1 and $3.4 \mathrm{nM}$ respectively), at least four orders of magnitude more efficient than uPA. PS-SCL (positional-scanning synthetic combinatorial peptide libraries) were used to identify consensus sequences for the TTSPs, which in the case of hepsin corresponded to the pro-HGF activation sequence, demonstrating
\end{abstract}

a high specificity for this reaction. Both TTSPs were also found to be efficient activators at the cell surface. Activation of pro-HGF by PC3 prostate carcinoma cells was abolished by both protease inhibition and matriptase-targeting siRNA (small interfering RNA), and scattering of MDCK (Madin-Darby canine kidney) cells in the presence of pro-HGF was abolished by inhibition of matriptase. Hepsin-transfected HEK (human embryonic kidney)293 cells also activated pro-HGF. These observations demonstrate that, in contrast with the UPA/uPAR system, the TTSPs matriptase and hepsin are direct pericellular activators of pro-HGF, and that together these proteins may form a pathway contributing to their involvement in pathological situations, including cancer.

Key words: hepatocyte growth factor (HGF), pericellular proteolysis, plasminogen activation, proteolytic processing, substrate specificity, type-II transmembrane serine protease (TTSP).

\section{INTRODUCTION}

HGF (hepatocyte growth factor), also known as scatter factor, is a polypeptide growth factor produced by mesenchymal cells that exerts pleiotropic effects in multiple tissues (reviewed in [1]). It is an important paracrine mediator of epithelial-mesenchymal cell interactions, affecting many cellular processes, including proliferation, differentiation, motility, invasion and branching morphogenesis. As well as being essential for development $[2,3]$, HGF is also implicated in a variety of physiological and pathological processes including wound healing, cancer and cardiovascular disease. These effects are all mediated by the binding of HGF to a single receptor, the proto-oncogene receptor tyrosine kinase c-Met [1].

HGF is closely related to the serine protease zymogen plasminogen, comprising an N-terminal PAN/apple domain, four kringle domains (compared with five in plasminogen) and a C-terminal serine protease domain. However, the latter is enzymatically inactive due in part to mutations in two of the three residues (His ${ }^{57}$ and $\mathrm{Ser}^{195}$; the numbering used for the serine protease domain follows the convention of numbering according to the sequence of chymotrypsinogen) comprising the serine protease catalytic triad. The primary binding determinants for the interaction of HGF with c-Met are contained within the $\mathrm{N}$ - terminal and kringle domains of HGF [4]. Although mediating high-affinity binding, these interactions are not sufficient for the activation of c-Met.

A key characteristic that HGF retains from its serine protease ancestry is the absolute requirement for limited proteolysis to acquire biological activity. In a similar manner to plasminogen and other serine protease zymogens, HGF is secreted as a single-chain precursor form and this pro-HGF form is devoid of signalling activity. Pro-HGF is activated to a disulphide-bridged, two-chain molecule by proteolytic cleavage at the canonical $\mathrm{Arg}^{15}-\mathrm{Val}^{16}$ bond in the serine protease domain. In the serine proteases, this cleavage results in conformational rearrangements in the so-called 'activation domain' and maturation of the active site. Structural studies have demonstrated that HGF undergoes corresponding conformational changes on proteolytic cleavage and that the rearranged activation domain constitutes an additional binding site for c-Met [5,6]. The binding of HGF to c-Met is also thought to involve a large-scale interdomain reorganization [6], also analogous to that observed in plasminogen [7]. Together these conformational changes, caused by a single proteolytic cleavage, enable HGF/c-Met signalling.

Proteolytic activation of pro-HGF clearly plays an essential role in the function of the HGF/c-Met signalling pathway; however, the proteases responsible for this key regulatory step and how

Abbreviations used: ECL, enhanced chemiluminescence; fXIla, Factor XIla; HEK, human embryonic kidney; HGF, hepatocyte growth factor; HGFA HGF activator; MDCK, Madin-Darby canine kidney; PS-SCL, positional-scanning synthetic combinatorial peptide libraries; siRNA, small interfering RNA; TMPRSS, transmembrane protease, serine; tPA, tissue plasminogen activator; TTSP, type-II transmembrane serine protease; uPA, urokinase plasminogen activator; uPAR, UPA receptor.

To whom correspondence should be addressed (email v.ellis@uea.ac.uk). 
the proteolysis is regulated are not well understood. The only protease unequivocally demonstrated to be an authentic activator of pro-HGF is the serine protease HGFA (HGF activator). This is an efficient activator of HGF in vitro [8] and has been shown to contribute to the activation of pro-HGF in vivo [9]. HGFA is activated by thrombin and, consistent with this, it has a role primarily at sites of tissue injury [10]. HGFA-null mice develop normally, in contrast with c-Met or HGF-null mice, but have a partial impairment of tissue repair [9].

Other serine proteases, several of which are pericellular proteases, have also been demonstrated to activate pro-HGF in vitro. They include both integral membrane proteins and proteases associated with membrane receptors or binding sites; these have key roles in regulating cell behaviour [11] and may act to regulate the activity of HGF on the surface of target cells, i.e. those expressing c-Met. Of particular interest in this respect is the plasminogen activator uPA (urokinase plasminogen activator), which has been proposed to be an important activator of HGF [12-15]. These studies were initially prompted by the homology of HGF and plasminogen, and would provide an attractive mechanism for the pericellular activation of $\mathrm{HGF}$, as the activity of UPA is promoted by association with its specific GPIanchored receptor UPAR (UPA receptor) on the surface of many cell types [16]. However, other studies have found no evidence for activation of pro-HGF by uPA in purified systems $[8,17]$. The activity of plasmin itself has also been implicated in the activation of pro-HGF [18,19]. Soluble forms of two TTSPs (typeII transmembrane serine proteases), matriptase [20] and hepsin $[21,22]$, have been shown to activate pro-HGF in purified systems, but their contribution in the pericellular environment is unclear.

In the present paper we assess the contribution of putative proteolytic activators of pro-HGF by quantitative comparison of their activities in solution, their P4-P1 substrate specificities and their activities in the pericellular environment. We find no evidence for activation of pro-HGF by uPA under a wide variety of conditions, making it unlikely that it has a biologically relevant role. In contrast, the TTSPs matriptase and hepsin were found to be efficient activators, both in solution and, more importantly, when expressed as transmembrane proteases. Together, these observations demonstrate that both matriptase and hepsin are effective proteolytic activators of pro-HGF at the cell surface, and furthermore that hepsin has specificity characteristics suggesting that it may be a highly selective activator of pro-HGF.

\section{EXPERIMENTAL}

\section{Proteins and reagents}

Human urinary uPA was from Merck Serono, pro-uPA was from Abbott, tPA (tissue plasminogen activator) was from Boerhinger Ingelheim, and fXIIa (Factor XIIa) and plasmin were from Enzyme Research Laboratories. Human HGFA was obtained from R\&D Systems and was activated using immobilized thrombin (Calbiochem). Recombinant human matriptase protease domain was expressed in Escherichia coli and yeast as described previously [23]. Soluble uPAR expressed in Drosophila S2 cells was a gift from Dr Michael Ploug (Finsen Laboratory, Copenhagen University Hospital, Copenhagen, Denmark). ProHGF expressed in Saccharomyces cerevisiae was a gift from $\mathrm{Dr}$ George Van Woude (Van Andel Research Institute, Grand Rapids, MI, U.S.A.). The matriptase inhibitor CJ-730 \{compound (8) in [24]\} was a gift from Dr Kerstin Uhland (Curacyte AG, Munich, Germany). The anti-matriptase monoclonal antibody M32 was a gift from Dr Chen-Yong Lin (Lombardi Cancer Center, Georgetown University Medical Center, Washington, DC, U.S.A.).

\section{Expression and purification of pro-HGF}

HGF cDNA was PCR-amplified from a random-hexamerprimed cDNA library, constructed from human fetal lung MRC-5 cells. PCR products were ligated into pGEM-T Easy (Promega), transformed into E. coli DH5 $\alpha$ and subcloned into the expression vector pMT-V5HisB. The resulting plasmid pMTHGF-V5His was co-transfected with pCoHygro into Drosophila Schneider S2 cells using CellFectin in serum-free Drosophila Expression Medium (all reagents from Invitrogen). After overnight incubation, cells were cultured for 2 days in complete medium at $27^{\circ} \mathrm{C}$ in atmospheric air then selected in 300$500 \mu \mathrm{g} / \mathrm{ml}$ hygromycin B for 5 weeks. Cells stably expressing HGF were adapted to serum-free medium and expression was induced with $0.5 \mathrm{mM} \mathrm{CuSO}_{4}$. Conditioned medium was collected after 7 days. Recombinant pro-HGF was purified from cleared S2-conditioned medium using metal chelate- and heparin-affinity chromatography. Conditioned medium was incubated overnight with Ni-NTA $\left(\mathrm{Ni}^{2+}\right.$-nitrilotriacetate) agarose (Qiagen) at $4{ }^{\circ} \mathrm{C}$, loaded on to a column and washed with $50 \mathrm{mM}$ sodium phosphate buffer, $\mathrm{pH} 8.0$, containing $0.3 \mathrm{M} \mathrm{NaCl}$ and $20 \mathrm{mM}$ imidazole. HGF was eluted in the same buffer containing $0.25 \mathrm{M}$ imidazole. The eluted protein was incubated with heparin-agarose (SigmaAldrich) in $10 \mathrm{mM}$ Tris $/ \mathrm{HCl}, \mathrm{pH} \mathrm{8.0,} \mathrm{overnight} \mathrm{at} 4{ }^{\circ} \mathrm{C}$ and was loaded on to a column and washed with $10 \mathrm{mM}$ Tris/ $\mathrm{HCl}$, $\mathrm{pH} 8.0$, containing $0.3 \mathrm{M} \mathrm{NaCl}$. Bound HGF was eluted in $10 \mathrm{mM}$ Tris/HCl, pH 8.0, containing $1.5 \mathrm{M} \mathrm{NaCl}$.

\section{Expression and purification of soluble hepsin}

Human hepsin was subcloned without the transmembrane domain, spanning residues 47-417. The honeybee melittin secretion signal sequence was appended to the N-terminus by PCR, and a $\mathrm{His}_{6}$ tag was appended to the C-terminus. All PCR products were inserted into pFastBac1 vector (Invitrogen) via EcoRI and NotI sites and were then sequenced. The resulting plasmids were used to produce recombinant baculovirus following the manufacturer's protocol (Invitrogen). Sf9 cells were infected at a MOI (multiplicity of infection) of 5-10 and the activity of hepsin in the supernatant monitored by hydrolysis of the fluorogenic peptide Ac-KRLRACC ( $N$-acetyl-Lys-Arg-Leu-Arg-7-amino-4-carbamoylmethylcoumarin). When maximal activity was achieved, the supernatant was collected, adjusted to $\mathrm{pH} 5.0$ with $4.0 \mathrm{M}$ sodium acetate and cleared by centrifugation $(15000 \mathrm{~g}$ for $10 \mathrm{~min})$. Filtered medium was loaded on to a Poros ${ }^{\circledR} \mathrm{HS}$ column on an $\mathrm{Akta}^{\mathrm{TM}}$ FPLC system (GE Healthcare) at $17 \mathrm{ml} / \mathrm{min}$ and was washed with $75 \mathrm{mM}$ sodium acetate, $\mathrm{pH}$ 5.0, until the baseline recovered. Bound proteins were eluted with $50 \mathrm{mM}$ Tris/ $\mathrm{HCl}, \mathrm{pH} 8.0$, containing $1.0 \mathrm{M} \mathrm{NaCl}$ and dialysed against $50 \mathrm{mM}$ Tris/ $\mathrm{HCl}$, pH 8.0, containing $20 \mathrm{mM} \mathrm{NaCl}$ overnight. The dialysed sample was loaded on to a benzamidine column at $1.5 \mathrm{ml} / \mathrm{min}$, washed with $50 \mathrm{mM}$ Tris/HCl, $\mathrm{pH} 8.0$, containing $0.2 \mathrm{M} \mathrm{NaCl}$ and eluted with $0.2 \mathrm{M}$ glycine, $\mathrm{pH} 3.0$. Eluted fractions were immediately neutralized with $2.0 \mathrm{M}$ Tris/ $\mathrm{HCl}, \mathrm{pH} 8.0$. The eluate was concentrated and further purified by Sephadex 200 chromatography (GE Healthcare) in $20 \mathrm{mM}$ Tris/ $\mathrm{HCl}$, pH 8.0, containing $0.15 \mathrm{M} \mathrm{NaCl}$. Active hepsin fractions were pooled and concentrated.

\section{Active-site titration}

The molar concentration of active sites for each protease was determined by active-site titration using 4-methylumbelliferyl $p$-guanidinobenzoate (Sigma-Aldrich). Proteases were dissolved in $50 \mathrm{mM}$ Hepes, $\mathrm{pH} 7.4$, containing $0.1 \mathrm{M} \mathrm{NaCl}$ and $0.01 \%$ 
Tween 80 and fluorescence was recorded at $25^{\circ} \mathrm{C}$ in a PerkinElmer LS50B luminescence spectrometer.

\section{Proteolytic activation of pro-HGF}

Recombinant single-chain pro-HGF (10 nM) was incubated with varying concentrations of the stated protease in $10 \mathrm{mM}$ sodium phosphate buffer, $\mathrm{pH} 8.0$, containing $0.12 \mathrm{M} \mathrm{NaCl}, 5 \mathrm{mM}$ EDTA and $0.01 \%$ Tween 80 for $1 \mathrm{~h}$ at $37^{\circ} \mathrm{C}$. In some experiments the reactions were also performed in $50 \mathrm{mM}$ Tris/ $\mathrm{HCl}, \mathrm{pH} 8.8$, containing $38 \mathrm{mM} \mathrm{NaCl}$ and $0.01 \%$ Tween 80 . Reactions were terminated by boiling in SDS/PAGE sample buffer containing $0.1 \mathrm{M}$ dithiothreitol. The samples were subjected to SDS/PAGE ( $10 \%$ gels), transferred on to PVDF membranes (Bio-Rad Laboratories) and the activation status of HGF determined by Western blotting using an anti-V5 monoclonal antibody (Invitrogen) and HRP (horseradish peroxidase)-conjugated rabbit anti-(mouse IgG) (Dako). The blots were incubated with ECL (enhanced chemiluminescence) Plus (GE Healthcare) and visualized either by exposure to Hyperfilm ECL (GE Healthcare) or by measuring chemiluminescence using a Storm PhosphorImager $^{\circledR}$ (GE Healthcare) and ImageQuant ${ }^{\circledR}$ software (Molecular Dynamics).

\section{Quantitative real-time PCR}

The expression of matriptase, hepsin, uPA and UPAR was determined in prostate-derived cell lines using reverse-transcribed total RNA and specific primer/probe sets in the 7500 Fast RealTime PCR System (Applied Biosystems), as described previously [25].

\section{Cellular activation of pro-HGF}

MDCK (Madin-Darby canine kidney), PC3 or hepsin-transfected HEK (human embryonic kidney)-293 cells were plated in 96-well plates at 20000 cells/well and cultured overnight. Cells were washed with PBS before incubation with pro-HGF in a total of $100 \mu \mathrm{l}$ of medium for up to $8 \mathrm{~h}$. Conditioned medium was removed, subjected to SDS/PAGE (10\% gels) and analysed for activation of pro-HGF by Western blotting.

\section{$K_{\mathrm{i}}$ determinations and combinatorial peptide library analysis}

Inhibition constants for the inhibitors CJ-730 and amiloride were determined using the substrate Ac-PRLR-AMC ( $N$-acetylPro-Arg-Leu-Arg-7-amino-4-methylcoumarin) for matriptase, hepsin and HGFA, and EGR-AMC (H-Glu-Gly-Arg-7-amino-4methylcoumarin) for uPA. Substrate hydrolysis was monitored at $25^{\circ} \mathrm{C}$ in a SpectraMax Gemini microplate spectrofluorometer (Molecular Devices). $K_{\mathrm{i}}$ values were determined from plots of $K_{\mathrm{m}} / V_{\max }$ against [I]. PS-SCL (positional-scanning synthetic combinatorial peptide libraries) were synthesized as described previously [26] and profiled with recombinant hepsin and matriptase (expressed in Saccharomyces cerevisiae).

\section{siRNA (small interfering RNA) knockdown of matriptase expression}

PC3 cells were transfected with either of two matriptase-specific siRNAs or universal control siRNAs as described previously [23]. Knockdown of matriptase expression was confirmed by Western blotting using the antibody M32, and was greater than $90 \%$ compared with both control siRNA and mock-transfected cells. Cells were analysed for pro-HGF activation $48 \mathrm{~h}$ after transfection.

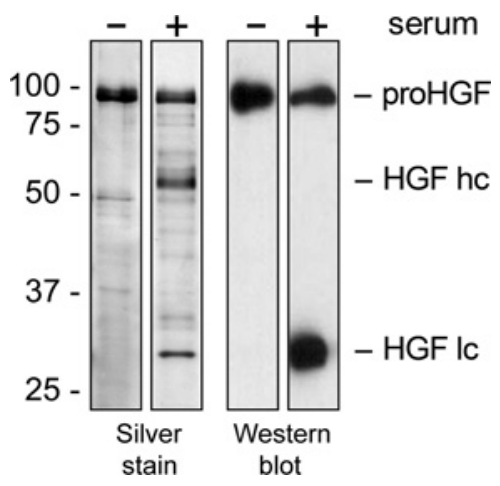

Figure 1 Expression and purification of pro-HGF

HGF was expressed in Drosophila S2 cells either in the presence (+) or absence (-) of serum and purified as described in the Experimental section. Samples $(50 \mathrm{ng})$ reduced with dithiothreitol were analysed by SDS/PAGE followed by either silver staining or Western blotting (probed for the C-terminal V5-epitope). For the Western blot, only the C-terminal light-chain of HGF (HGF Ic) is detected subsequent to proteolytic activation. HGF hc, HGF heavy-chain.

\section{Generation of cell lines stably expressing hepsin}

Full-length hepsin cDNA [IMAGE (Integrated Molecular Analysis of Genomes and their Expression) clone 5228525] was ligated into pcDNA3.1(+)-HA to generate the plasmid pcDNA3.1/HPN-HA and was transfected into HEK-293 cells using Fugene 6 (Roche); cells were selected for stable expression in $200 \mu \mathrm{g} / \mathrm{ml} \mathrm{Zeocin}{ }^{\mathrm{TM}}$ (Invitrogen). Clones were tested for hepsin expression by Western blotting using an anti-HA (haemagglutinin) antibody and by TaqMan $^{\circledR}$ quantitative realtime PCR using an ABI Prism ${ }^{\circledR} 7700$ instrument (Applied Biosystems). Two clones stably expressing low and high levels of hepsin were selected (clones F10 and C6 respectively).

\section{MDCK cell scatter assay}

MDCK cells were seeded at a density of $10^{3}$ cells per well and left to adhere overnight. Cells were washed with serum-free medium and treated with $10 \mathrm{ng} / \mathrm{ml}$ of either active or pro-HGF, in the presence or absence of $50 \mu \mathrm{M} \mathrm{CJ}-730$. After $30 \mathrm{~h}$ cells were washed with PBS and fixed with ice-cold methanol. Images were taken using a Zeiss inverted microscope fitted with a CCD (chargecoupled-device) camera using $10 \times$ objective. Three independent experiments were performed with all treatments in duplicate.

\section{RESULTS}

\section{Expression of recombinant single-chain pro-HGF}

The study of the proteolytic activation of HGF is greatly facilitated by the availability of homogenous preparations of the single-chain form of the protein, a problem which has hampered some previous studies. We expressed HGF in Drosophila S2 cells and, under serum-free conditions, the recombinant protein was exclusively in the $92 \mathrm{kDa}$ unactivated, single-chain form, as shown by SDS/PAGE with reduced samples (Figure 1). In contrast, in serum-containing medium, there was significant activation of HGF, as shown by the appearance of both the $55 \mathrm{kDa}$-terminal heavy-chain and the $34 \mathrm{kDa} C$-terminal light-chain. In some of the experiments described below, a small amount of activated HGF can be detected due to the high sample loading, which was necessary to ensure the detection of low levels of pro-HGF activation. 



\section{Figure 2 Proteolytic activation of HGF by uPA}

Pro-HGF was incubated with varying concentrations of uPA for $1 \mathrm{~h}$ at $37^{\circ} \mathrm{C}$. (A and B) HGF expressed in S2 cells was analysed by SDS/PAGE and detected by Western blotting for the C-terminal V5-epitope. (A) Lane 1, 0 nM uPA control; lanes 2-8, 1, 5, 10, 15, 30, 50 and $100 \mathrm{nM}$ uPA. (B) Lanes 1, 6 and 11, $0 \mathrm{nM}$ uPA controls; lanes 2-5, 8.3, 17, 83 and 167 nM uPA; lanes 7-10, 0.83, 1.7, 3.1 and $6.2 \mu \mathrm{M}$ uPA. (C) HGF expressed in S. cerevisiae was analysed by SDS/PAGE with silver-stained gels. Lanes 1 and 10, 0 nM uPA controls; lanes 2-8; 0.14, 0.71, 1.4, 2.1, 4.3, 7.1 and $14 \mathrm{nM}$ uPA; lane 9 , HGF fully activated by $10 \mathrm{nM}$ HGFA. (D) shows the effect of $0.8 \mu \mathrm{M}$ uPA and $100 \mu \mathrm{g} / \mathrm{ml}$ heparin and (E) the effect of $2.5 \mu \mathrm{M}$ uPA and $2.5 \mu \mathrm{M}$ suPAR (soluble uPAR) on the proteolytic activation of $\mathrm{S} 2$ cell-expressed pro-HGF as indicated. HGF hc, HGF heavy-chain; HGF Ic, HGF light-chain.

\section{uPA is not an efficient activator of pro-HGF}

To investigate the role of uPA in the activation of HGF, a fixed concentration of pro-HGF was incubated with varying concentrations of uPA for $1 \mathrm{~h}$ at $37^{\circ} \mathrm{C}$ and samples were analysed by SDS/PAGE followed by Western blotting. The latter was necessary as pro-HGF was used at a relatively low concentration $(10 \mathrm{nM})$ in these experiments, so as to be below the likely $K_{\mathrm{m}}$ for the reaction, thereby increasing the fractional amount of substrate hydrolysed. However, no activation of HGF was observed with concentrations of uPA up to $50 \mathrm{nM}$ (Figure 2A), with no reduction in the intensity of the $92 \mathrm{kDa}$ pro-HGF band nor an increase in the $34 \mathrm{kDa}$ HGF light-chain band. Increasing incubation times for up to $5 \mathrm{~h}$ also failed to demonstrate any activation of pro-HGF (results not shown). Subsequently, the concentration of uPA was increased up to $3 \mu \mathrm{M}$ (Figure 2B). Even under these conditions no activation of pro-HGF was apparent, with no increase in the intensity of the $34 \mathrm{kDa}$ light-chain band. However, a reduction in the intensity of both this and the proHGF band was observed, which was probably due to non-specific proteolytic cleavage of the C-terminal epitope tag at this extremely high concentration of uPA. Consistent with this interpretation, non-reduced samples also showed a decrease in intensity of the single band representing both molecular forms of HGF (results not shown).

To exclude the possibility that the lack of observed pro-HGF activation was an artefact, possibly caused by expression of HGF in Drosophila S2 cells or the presence of the C-terminal epitope tag, similar experiments were performed with wild-type HGF expressed in $S$. cerevisiae. Once again, no activation by uPA was detectable, although the pro-HGF was readily activated by a low concentration of HGFA (Figure 2C). In addition, the experiment shown in Figure 2(A) was repeated under identical conditions but with the inclusion of plasminogen. Activation of plasminogen was readily detected at uPA concentrations as low as $0.2 \mathrm{nM}$ (results not shown), demonstrating that uPA could activate plasminogen, but not pro-HGF, in the same reaction mixture.

The uPA used for these experiments was purified from urine and is known to have a heterogeneous heavy- or A-chain terminating in Pro ${ }^{155}, \mathrm{Arg}^{156}$ or Phe ${ }^{157}$, rather than the expected Lys ${ }^{158}$, due to the action of carboxypeptidases [27]. It is possible that the lack of the C-terminal Lys ${ }^{158}$ renders these forms of uPA unable to activate pro-HGF, as this residue is thought to be involved in the plasminogen activator activity of uPA under certain conditions [28]. Similarly, single-chain pro-uPA itself has been reported to have significant plasminogen activator activity [29]. However, neither pro-uPA nor uPA with an intact A-chain, prepared by plasmin activation of pro-uPA, were able to activate pro-HGF in experiments similar to those described above (results not shown). tPA, up to a concentration of $5 \mu \mathrm{M}$, was also unable to activate pro-HGF (results not shown).

HGF can bind to both heparan sulphate and heparin, which leads to effects on its biological activity by increasing binding to c-Met [30]. uPA has also been reported to bind heparin via its kringle domain [31]. As interactions between heparin-binding proteases and their substrates or inhibitors can be promoted by coincident binding to heparin, the effect of heparin on the activation of pro-HGF by uPA was investigated. As shown in Figure 2(D), the presence of heparin did not lead to any detectable activation of HGF.

To determine whether the binding of uPA to its receptor protein UPAR influenced the activation of pro-HGF, these experiments were repeated in the presence of equimolar amounts of soluble UPAR. Once again, no activation of pro-HGF was apparent (Figure 2E). 

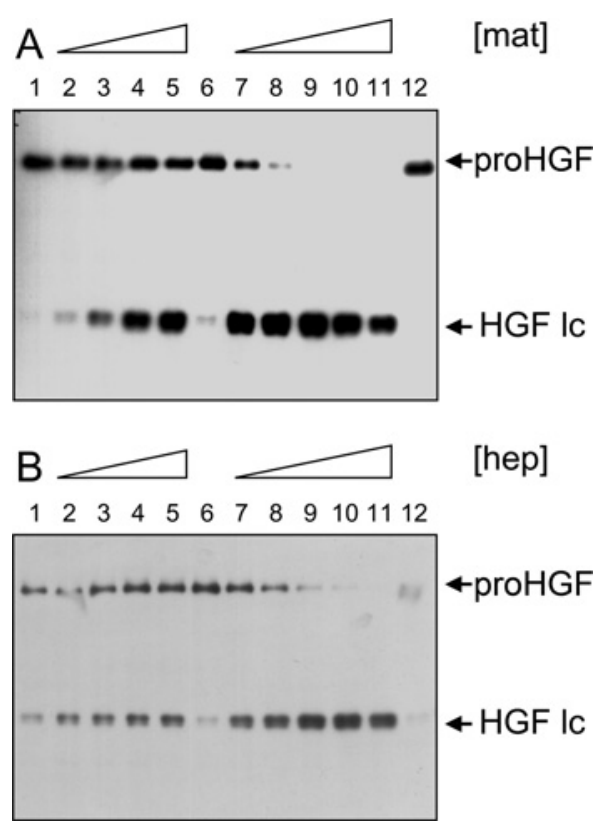

Figure 3 Proteolytic activation of HGF by matriptase and hepsin in solution

Pro-HGF expressed in S2 cells was incubated with varying concentrations of either the matriptase catalytic domain or the hepsin extracellular domain for 1 -h at $37^{\circ} \mathrm{C}$. Activation was detected by SDS/PAGE followed by Western blotting for the C-terminal V5-epitope. (A) Matriptase (mat) and (B) hepsin (hep). Lanes 1, 6 and 12, 0 nM protease; lanes $2-5$ and $7-11 ; 0.1,0.25,0.5,1$, 2, 4, 8, 16 and 32 nM protease. HGF Ic, HGF light-chain.

\section{Alternative molecular forms of HGF}

When we isolated the cDNA for HGF, half of the clones sequenced were found to represent a previously described alternatively spliced variant lacking five residues $\left(S^{130}\right.$ FLPS $\left.^{134}\right)$ in the first kringle domain. As the relative abundance of the clones suggested that this variant may represent a substantial proportion of HGF in vivo, this form was also expressed in $\mathrm{S} 2$ cells and its activation studied. Again, activation of $\Delta 130-134$ pro-HGF by uPA was not detected, but it was activated by HGFA with similar efficiency to the full-length protein (results not shown).

\section{Soluble forms of matriptase and hepsin efficiently activate pro-HGF}

On the basis of the biochemical data in the present paper, it appears unlikely that uPA could play any significant role in the biological activation of pro-HGF. However, members of the TTSP family may be good candidates, due to their membrane localization. In sharp contrast with uPA, the isolated catalytic domain of matriptase was found to be a very efficient activator of pro-HGF, with activation apparent at sub-nanomolar concentrations of the protease (Figure 3A). This proteolysis was also specific as no other proteolytic fragments were observed on silver-stained gels (results not shown). Similar experiments were performed with a soluble form of hepsin consisting of the complete extracellular domain (residues 47-417). Soluble hepsin was also observed to be an efficient and specific activator of pro-HGF (Figure 3B).

\section{Quantitative comparison of pro-HGF activation}

To quantitatively compare the efficiency of pro-HGF activation by the various proteases, the molar concentration of the protease active sites was first determined by active-site titration. Varying concentrations of the proteases were incubated with a fixed concentration of pro-HGF and the samples were then

\section{Table 1 Relative efficiencies of various proteolytic activators of HGF}

The concentration of each protease giving $50 \%$ activation of pro-HGF in $1 \mathrm{~h}$ was calculated by fitting the data from titration curves obtained using at least nine different concentrations of each protease over a 1000-fold dilution range (results shown in Supplementary Figure S1) and represent means \pm S.D. Incubation with plasmin led to extensive degradation of HGF at higher concentrations and it was not possible to accurately quantify activation. No activation was detected with either UPA or IPA at the highest concentrations used (approx. $6 \mu \mathrm{M}$ ), and results are calculated using a conservative detection limit of $20 \%$ activation. Pro-HGF activating activity is expressed relative to HGFA, which is set at $100 \%$.

\begin{tabular}{lcl}
\hline Protease & Concentration givng $50 \%$ activation (nM) & Relative activity (\%) \\
\hline HGFA & $0.250 \pm 0.059$ & 100 \\
Matriptase & $0.121 \pm 0.027$ & 207 \\
Hepsin & $3.39 \pm 1.08$ & 7.4 \\
fXIla & $14.0 \pm 6.95$ & 1.8 \\
Plasmin & $>50 \mathrm{nM}$ & $<0.5$ \\
UPA & $>30 \mu \mathrm{M}$ & $<0.001$ \\
tPA & $>30 \mu \mathrm{M}$ & $<0.001$
\end{tabular}

subjected to SDS/PAGE and Western blotting for the Cterminal V5 epitope (see Supplementary Figure S1 available at http://www.BiochemJ.org/bj/426/bj4260219add.htm). Activation was quantified as the ratio of the intensities of the activated light-chain band to the sum of the light-chain and non-cleaved single-chain bands, and expressed as the concentration of protease necessary to achieve $50 \%$ activation of pro-HGF in $1 \mathrm{~h}$ (Table 1 ). These results show matriptase to be the most efficient activator under these conditions, with approx. twice the activity of HGFA. A known relatively weak activator, fXIIa [8], was found to be approximately 100 -fold less active than matriptase. However, activation of pro-HGF by either of the plasminogen activators under these conditions was estimated to be at least four to five orders of magnitude below that observed with hepsin and matriptase respectively.

\section{Peptide substrate specificities of matriptase and hepsin}

As matriptase and hepsin appear to share a similar protein substrate specificity as relatively efficient activators of pro-HGF, the P4-P1 peptide substrate specificities of these two proteases were compared using fluorogenic PS-SCL with diversity at all four positions [26]. Both proteases have trypsin-like activity, with primary specificity for arginine and lysine residues. The results show that matriptase has no real arginine/lysine preference at P1 (Supplementary Figure S2A available at http://www.BiochemJ.org/bj/426/bj4260219add.htm). In contrast, hepsin has a very strong preference for an arginine residue (Supplementary Figure S2B). The optimal P4-P1 substrate preference for hepsin sequence is Lys-Gln-Leu-Arg (Figure 4), which exactly matches the activation sequence of pro-HGF. In contrast, the specificity of matriptase does not match this sequence well, with the P3-P2 combination of Gln-Leu being particularly disfavoured, as shown by both the single-fixed position (Figure 4) and the two-fixed position (Supplementary Figure S2A, upper two rows) libraries. Therefore although the data from the kinetic experiments demonstrate that matriptase is the more efficient activator of pro-HGF, these experiments suggest that hepsin has a greater specificity for this reaction.

\section{Cellular activation of pro-HGF by matriptase}

Matriptase, hepsin and uPA are three of the serine proteases most often found to be up-regulated in a wide variety of cancers, for example, in prostate cancer all three are up-regulated together with UPAR. However, only matriptase and hepsin show a strong 


\section{A. Matriptase}

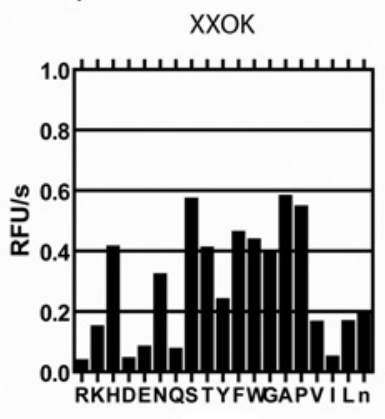

P2

B. Hepsin

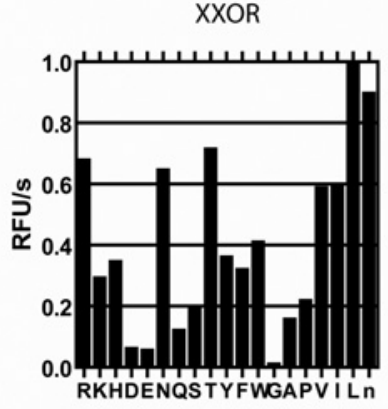

P2
XOXK

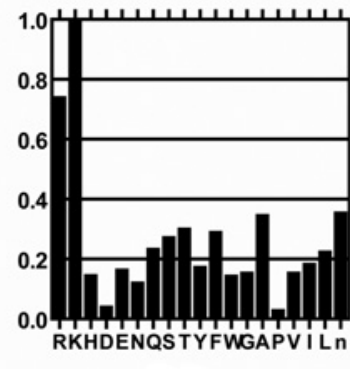

P3

XOXR

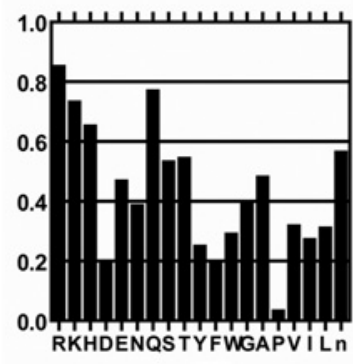

P3
OXXK

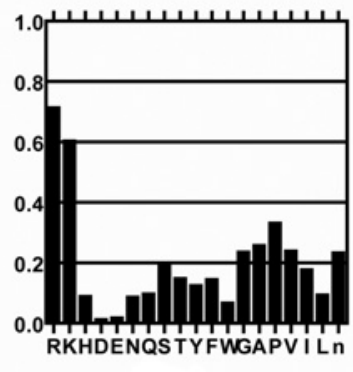

P4

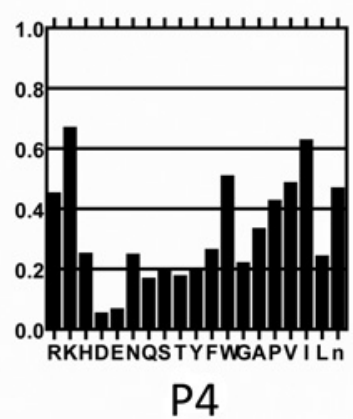

Figure 4 Peptide substrate specificities of matriptase and hepsin in P4-P1 PS-SCL

(A) Matriptase and (B) hepsin substrate preferences were determined in vitro using peptide substrates in fluorogenic assays as described in the Experimental section. In each panel, the initial velocities of P2, P3, and P4 positions when P1 is fixed (P1 fixed at arginine for hepsin and P1 fixed at lysine for matriptase) are presented. X represents the 19-amino acid equimolar mixture (the mixture excludes cysteine, and methionine is replaced with the isostere norleucine, $\mathrm{n}$ ), and 0 represents the single fixed amino acid. The full data set is presented in Supplementary Figure S2. RFU, relative fluorescence units.

\section{Table 2 Expression of TTSPs by prostate cell lines}

Expression of matriptase and hepsin in prostate cell lines was determined by quantitative real-time PCR (TaqMan ${ }^{\circledR}$ ). Results are shown for PNT1a, an SV40-transformed normal prostate epithelial cell line, and for three prostate carcinoma cells lines, PC3, LNCaP and DU145. Relative mRNA levels are shown after normalization for 18S rRNA and are gene-specific. N.D. not determined.

\begin{tabular}{lllll}
\hline Cell line & Matriptase & Hepsin & UPA & UPAR \\
\hline PNT1a & $<1$ & $<1$ & N.D. & N.D. \\
PC3 & 140 & $<1$ & 160 & 120 \\
LNCaP & 32 & 380 & $<1$ & 5 \\
DU145 & $<1$ & $<1$ & 230 & 90
\end{tabular}

correlation with malignancy and they have expression restricted to malignant epithelial cells, which is the site of c-Met expression [25]. Therefore we sought to determine whether various prostate cancer cell lines could activate pro-HGF and whether either of the TTSPs, hepsin or matriptase, were responsible. Relative expression of hepsin and matriptase in these cells was determined by quantitative real-time PCR (Table 2).

PC3 cells, which expressed the highest levels of matriptase but were devoid of hepsin expression, were found to activate pro-HGF in a time-dependent manner over a $24 \mathrm{~h}$ time period (Figure 5A). To determine whether this activation was catalysed by matriptase, we used a matriptase-selective, 3-amidinophenylalanine-based inhibitor CJ-730 (Figure 5B). CJ-730 inhibits matriptase $\left(K_{\mathrm{i}}=\right.$ $40 \mathrm{nM})$ [24] and hepsin $\left(K_{\mathrm{i}}=185 \mathrm{nM}\right)$ (K.A. Owen and $\mathrm{V}$. Ellis, unpublished work) and consistent with this the $\mathrm{IC}_{50}$ for inhibition of pro-HGF activation by matriptase in solution was approximately $50 \mathrm{nM}$ (results not shown). However, although CJ730 could completely inhibit pro-HGF activation in PC3 cells, the $\mathrm{IC}_{50}$ value was determined to be approx. $5 \mu \mathrm{M}, 100$-fold above the $K_{\mathrm{i}}$ value. This discrepancy suggested that the inhibitory effect was possibly due to non-specific inhibition of proteases other than matriptase. Therefore to further substantiate the role of matriptase in PC3 cells, matriptase expression was knocked down with matriptase-targeting siRNA, which also effectively and specifically abolished pro-HGF activation (Figure 5B).

Although activation of pro-HGF can be blocked by inhibition or down-regulation of matriptase, this could be an indirect effect, as matriptase has been shown to activate pro-uPA both in solution $[20,32]$ and on the cell surface [23]. To test whether uPA had any role in the activation of pro-HGF under these conditions, an inhibitor of uPA, amiloride $\left(K_{\mathrm{i}}=3.6 \mu \mathrm{M}\right)$ (K.A. Owen and V. Ellis, unpublished work), was used. Amiloride at concentrations of up to $1 \mathrm{mM}$ failed to inhibit the activation of pro-HGF on either PC3 (Figure 5B) or MDCK cells (results not shown), consistent with the inability of uPA to activate pro-HGF either in solution, in the presence or absence of UPAR, or on the cell surface.

To confirm that the proteolytic cleavage of pro-HGF by matriptase led to the generation of biologically active HGF, the cell-scattering activity of HGF was determined using MDCK cells. When incubated with either active HGF (Figure 5D) or proHGF (Figure 5E) the cells were observed to scatter, compared with the tightly packed groups of cells observed in the absence of HGF (Figure 5C). Pro-HGF-mediated scattering was prevented by the inclusion of CJ-730, consistent with the inhibition of matriptasecatalysed pro-HGF activation (Figure 5F). 


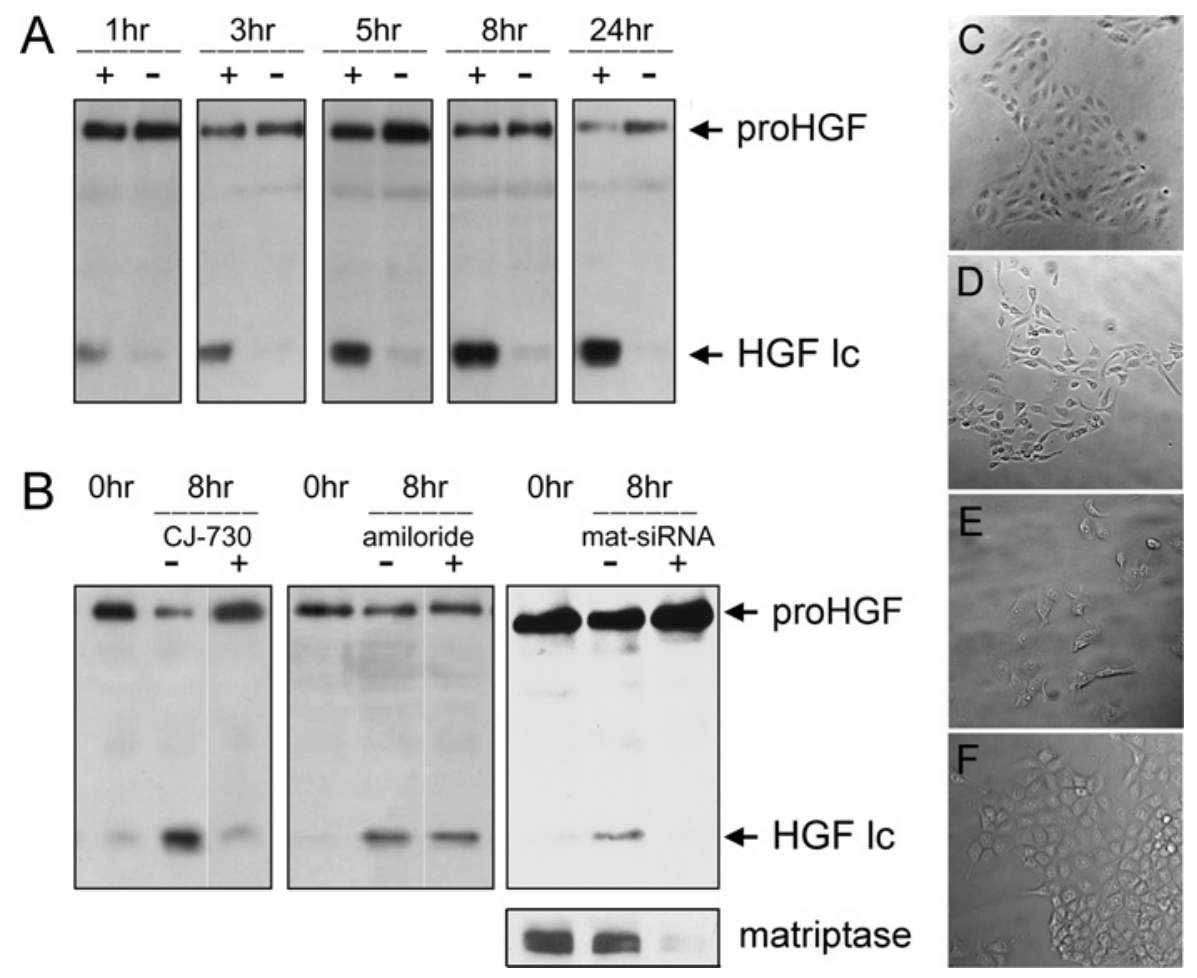

Figure 5 Activation of pro-HGF on the surface of cells expressing transmembrane matriptase

(A) Time course of activation of pro-HGF by PC3 cells. Pro-HGF was incubated in serum-free medium in the presence (+) and absence (-) of PC3 cells. Conditioned medium was removed at the indicated time points and analysed for HGF activation by Western blotting for the C-terminal V5 epitope. (B) PC3 cells were incubated with pro-HGF for $8 \mathrm{~h}$ in the presence (+) and absence (-) of $50 \mu \mathrm{M}$ matriptase inhibitor CJ-730 or $1 \mathrm{mM}$ uPA inhibitor amiloride. HGF activation was analysed as above. HGF activation data are also shown for cells pre-treated with matriptase-specific (mat-siRNA) (+) or control (-) siRNA, together with Western blots for matriptase to demonstrate the efficiency of knockdown. In these cellular activation experiments, slight variations in the level of pro-HGF activation were observed in the different control conditions, but in all cases time- and cell-dependent activation of HGF was clearly observed. (C-F) HGF-mediated MCDK cell scattering. MDCK cells growing as tight colonies were incubated in the presence or absence of HGF and cell scattering was determined after $30 \mathrm{~h}$. (C) Control MCDK cells in the absence of added HGF. (D) MDCK cells incubated with active HGF. (E) MDCK cells incubated with pro-HGF. (F) MDCK cells incubated with pro-HGF in the presence of CJ-730. No effect of CJ-730 was observed when included in incubations with active HGF. HGF IC, HGF light-chain.

\section{Cellular activation of pro-HGF by hepsin}

Among the panel of prostate cell lines, LNCaP expresses significant levels of hepsin but, despite the relative efficiency and high specificity of hepsin observed in solution, these cells did not activate pro-HGF above the level of the control PNT1a cell line (results not shown). Therefore to determine whether transmembrane hepsin could also activate pro-HGF in the context of the cell surface, hepsin-negative HEK-293 cells were stably transfected with full-length hepsin. Two clones were selected with differing levels of hepsin expression. Figure 6 shows robust activation of pro-HGF in the highest expressing clone C6 over a period of $5 \mathrm{~h}$ and significant activation was also observed with the lower expressing F10 clone, by comparison with the parental HEK-293 cell line. Therefore in these cells, membrane-anchored hepsin can efficiently activate pro-HGF at the cell surface.

\section{DISCUSSION}

The biological activity of HGF is strictly dependent on proteolytic processing at a canonical site equivalent to the $\operatorname{Arg}^{15}-\mathrm{Ile}^{16}$ bond of chymotrypsinogen, which it retains from its catalytically active serine protease homologues. It seems likely that multiple proteases are able to catalyse this cleavage in vivo, at least in terms of development and normal physiology. None of the existing knockouts of serine proteases in mice, which includes all of the proteases studied here, phenocopy the embryonic lethal

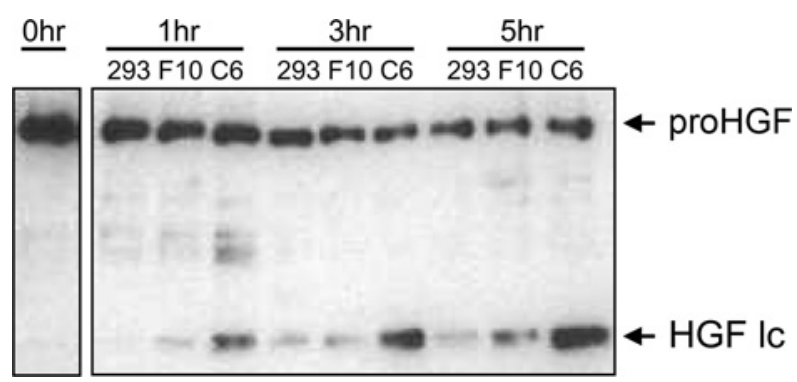

Figure 6 Activation of pro-HGF on the surface of cells expressing transmembrane hepsin

Parental HEK-293 cells and hepsin-transfected HEK-293 cell clones F10 and C6 were incubated with pro-HGF for the indicated times and HGF activation analysed by Western blotting for the C-terminal V5 epitope. Relative hepsin expression in the three cell lines as determined by quantitative real-time PCR was $<0.01$ for HEK-293 cells, 0.25 for the F10 clone and 1.0 for the C6 clone. HGF Ic, HGF light-chain.

phenotype observed in HGF-knockout mice [2,3]. The aim of this study was to determine which of the serine proteases reported previously to be capable of activating pro-HGF are most likely to have a biologically relevant role, based on their enzyme kinetic properties, substrate specificities and their ability to activate proHGF in the pericellular environment.

In this study we find no evidence that the plasminogen activator UPA is a significant activator of pro-HGF, using an 


\section{Table 3 Substrate cleavage specificities of TTSPs and plasminogen activators}

The zymogen activation cleavage sequences of pro-HGF are shown together with the cleavage sequences of the authentic uPA protein substrates plasminogen and uPAR, and the activation cleavage sequences of hepsin and matriptase zymogens. For comparison, the peptide substrate preferences of hepsin and matriptase determined using PS-SCL are shown, together with the substrate preference of uPA determined previously using a phage-display library [34].

\begin{tabular}{lllll}
\hline Substrate & P4 & P3 & P2 & P1 \\
\hline Pro-HGF & Lys & Glu & Leu & Arg \\
Plasminogen (human) & Cys & Pro & Gly & Arg \\
Plasminogen (bovine) & Cys & Ser & Gly & Arg \\
uPAR & Asp & Ser & Gly & Arg \\
Matriptase zymogen & Arg & Glu & Ala & Arg \\
Hepsin zymogen & Pro & Val & Asp & Arg \\
Hepsin PS-SCL concensus & Lys & Glu & Leu & Arg \\
Matriptase PS-SCL consensus & Lys/Arg & Lys/Arg & Ser/Ala/Pro & Lys/Arg \\
uPA phage consensus & & Ser & Gly & Arg
\end{tabular}

exhaustive range of experimental conditions. These include various molecular forms of uPA, various molecular forms and splice variants of pro-HGF, and the presence of uPAR and heparin. This is surprising in light of the previous reports of activation by uPA, but perhaps unsurprising when the known substrate specificity of uPA is considered. UPA is a highly specific serine protease. Its only authenticated protein substrate, in addition to plasminogen, is its own receptor UPAR [33], which is cleaved at a sequence closely resembling the zymogen activation sequence of plasminogen (Table 3). In contrast, the activation sequence in pro-HGF resembles neither the sequence of plasminogen nor peptide sequences identified as optimal for UPA using a substrate phage-display approach [34] (Table 3). Furthermore, analysis of results from the latter study reveals that none of the 91 substrate phage clones selected had the HGF residues at P2 or P3 (leucine and glutamine respectively). uPA-specific substrates are dominated by those with a glycine reside at P2 (Table 3), and large hydrophobic residues are excluded at this position, consistent with the unusually restricted S2 pocket in uPA. Therefore there is no prior reason to suppose that pro-HGF would be a substrate for uPA.

The reason for the discrepancy between these conclusions is not immediately apparent, but three observations may have a bearing on it. First, it has been reported that the activation by uPA involves a 'stoichiometric' interaction between uPA and proHGF [13], rather than the catalytic reaction that would be expected. Secondly, the effect of uPA has been reported to be strongly affected by ionic strength [15]. Thirdly, the same study also found that the catalytic domain of uPA alone was unable to activate pro-HGF. None of these observations are characteristic of a typical protease-substrate interaction. The observation of pro-HGF activation at very low ionic strength [15] suggests that it is driven by electrostatic interactions, possibly of a nonspecific nature. Consistent with this, the N-terminal kringle and connecting peptide region of uPA are highly basic with a pI of 9.4, whereas the region of HGF spanning kringles 3 and 4 is acidic with a pI of 4.8. Therefore non-specific electrostatic interactions between the $\mathrm{N}$-terminal regions of the two proteins, promoted at low ionic strength, may underlie the observed activation by uPA. Nevertheless, we do not observe activation under similar conditions and we have been unable to demonstrate such an interaction between uPA and pro-HGF using a co-immunoprecipitation approach (K.A. Owen, D. Qiu and V. Ellis, unpublished work). An additional consideration is that the majority of previous studies have used ${ }^{125}$ I-labelled HGF. Our approach of detecting activation by Western blotting for a C-terminal V5 epitope obviates the need for such chemical modification, and the introduction of artefacts by the presence of the C-terminal tag is unlikely as we obtained identical results using wild-type HGF.

In sharp contrast with the lack of activity of uPA, both the TTSPs matriptase and hepsin proved to be efficient activators of pro-HGF. Our quantitative results demonstrate that matriptase is the most efficient of the known activators, with hepsin having a lower, but nevertheless substantial, activity. As with previous qualitative studies [20-22], our quantitative studies utilized truncated soluble forms of the proteases. However, we further demonstrated that the full-length transmembrane forms of both matriptase and hepsin efficiently activated pro-HGF at the cell surface. This would appear to give both matriptase and hepsin a significant advantage over HGFA, a soluble protease, as activated HGF can be specifically generated at its site of action. In most tissues, HGF is expressed by cells of mesenchymal origin, whereas c-Met, matriptase and hepsin are expressed by epithelial cells. Therefore although HGF is a paracrine factor, its activation could be considered to be autocrine. However, it remains to be determined whether membrane localization of these proteases confers them with any kinetic advantage and whether their N-terminal domains are involved in substrate recognition or presentation, for example by exosite interactions.

Although HGF activation by matriptase on PC3 cells was readily detected, no activation was observed on $\mathrm{LNCaP}$ cells which express significant amounts of hepsin. This may be due in part to the lower efficiency of hepsin as an activator of pro-HGF in comparison with matriptase, but may also reflect varying levels of the active forms of these proteases on the cell surface, an issue that is discussed subsequently. However, the observation of robust activation on hepsin-transfected HEK-293 cells demonstrates that, under suitable conditions, both of these TTSPs can have potentially significant roles as activators of pro-HGF.

The P4-P1 substrate specificity of matriptase and hepsin, determined using PS-SCL, in which one position is varied at a time, revealed that hepsin has a very clear preference for arginine at P1, whereas matriptase does not discriminate between arginine and lysine at this position, in accordance with results published previously [21,32]. This is consistent with the presence of an arginine residue at $\mathrm{P} 1$ of the pro-HGF activation sequence (LysGln-Leu-Arg). Interestingly the PS-SCL consensus for hepsin exactly matches the pro-HGF activation sequence (Table 3), whereas the consensus for matriptase does not, and is particularly disfavoured at the P3-P2 sequence of Gln-Leu. Serine protease substrate specificity often does not conform well to linear peptide 
sequences, due in part to conformational constrains in the substrate. Therefore the close agreement in the case of hepsin suggests that the core P4-P1 sequence of pro-HGF may be sufficient for recognition by hepsin, whereas additional features of the pro-HGF sequence and/or fold may be needed to contribute to its activation by matriptase.

A significant corollary of the observed pericellular activation of pro-HGF is that these TTSPs must possess a significant degree of proteolytic activity under the conditions used, and therefore that they have become activated from their singlechain zymogen forms. Unusually for serine protease zymogens, some TTSPs appear to have the capacity for autoactivation when expressed as soluble truncated forms. This has been observed for both matriptase and hepsin, and also TMPRSS2 (transmembrane protease, serine 2), TMPRSS3, matriptase2/TMPRSS6 and matriptase-3/TMPRSS7 [34a]. We have also observed autoactivation of full-length transmembrane hepsin (D. Qiu and V. Ellis, unpublished observations).

Activation of serine protease zymogens is a highly regulated process, and autoactivation is usually prevented by the sequence $\mathrm{N}$-terminal of the proteolytic activation site being incompatible with the substrate specificity of the active protease. Analysis of the activation sequences of matriptase and hepsin (Table 3), reveals that the matriptase sequence is a reasonable match to its own substrate specificity, although the hepsin sequence contains a disfavoured aspartate residue at P2. Therefore although autoactivation of these protease zymogens can be demonstrated, its efficiency and functional relevance has yet to be demonstrated.

Despite the lack of direct activation by uPA, compelling evidence that the plasminogen activation system has a role in the biological activity of HGF comes from in vivo observations in mice deficient in components of this proteolytic system. For example, liver regeneration is impaired in both uPA- and plasminogen-null mice, concomitantly with a reduction in proHGF activation [19,35]. However, these observations do not demonstrate a direct role for UPA, or plasmin. HGF is known to associate with components of the extracellular matrix, including heparan sulphate proteoglycan, thrombospondin, fibronectin and vitronectin [36,37]. The activity of the plasminogen activation system can lead to the degradation of these components, either directly or by plasmin activation of matrix metalloproteases, and plasminogen-dependent release of HGF from the extracellular matrix has been demonstrated [18]. The activation of proHGF is also increased in mice null for TIMP (tissue inhibitor of metalloproteinases)-1 [38], consistent with an increase in matrix metalloprotease-mediated extracellular matrix degradation. Therefore it appears likely that the role of the plasminogen activation system in the activation of HGF is in releasing sequestered pro-HGF from the extracellular matrix, making it available for pericellular activation by transmembrane serine proteases.

The activation of pro-HGF in vivo is clearly redundant and mediated by a variety of proteases. However, this does not rule out the involvement of individual proteases in specific situations, especially pathological situations, and may be of particular relevance in cancer. Although c-Met is a proto-oncogene, and activating mutations are found in many cancers, its activation by HGF is thought to play an important role in oncogenesis and tumour development [1] and there is evidence that increased $\mathrm{HGF} / \mathrm{c}-\mathrm{Met}$ signalling promotes the progression of prostate cancer [39]. We have shown in an analysis of 40 protease-related genes in prostate cancer that the expression of both matriptase and hepsin is highly correlated with both malignancy and disease progression, and that hepsin was the protease gene most highly correlated with disease stage [25]. Therefore it is possible that the activation of pro-HGF by either matriptase or hepsin provides a mechanism for the involvement of these TTSPs in the development of cancer.

\section{AUTHOR CONTRIBUTION}

Jennifer Harris and Vincent Ellis developed the project, designed the experiments and analysed the data. Kate Owen performed the majority of experiments, which formed the basis of her $\mathrm{PhD}$ thesis, and contributed to the experimental design, data analysis and writing of the paper. Deyi Qiu generated the hepsin-transfected 293 cells and performed associated experiments. Juliano Alves, Andrew Schumacher and Jun Li expressed and purified recombinant hepsin and matriptase, and profiled the substrate specificity in the peptide substrate libraries. Lynette Kilpatrick contributed to the initial stages of the project. Vincent Ellis wrote the paper. All authors discussed the results and their implications, and commented on the manuscript at all stages.

\section{ACKNOWLEDGEMENTS}

We thank George Van Woude, Michael Ploug, Kerstin Uhland and Chen-Yong Lin for their generous gifts of reagents.

\section{FUNDING}

This work was supported by grants and fellowship awards from the British Heart Foundation [grant numbers FS/99073, FS/2001040, PG/04/037]; the Norfolk and Waveney Big C Appeal; and by the European Union Framework Programme 6 Cancerdegradome Project [grant number LSHC-CT-2003-503297].

\section{REFERENCES}

1 Birchmeier, C., Birchmeier, W., Gherardi, E. and Vande Woude, G. F. (2003) Met, metastasis, motility and more. Nat. Rev. Mol. Cell Biol. 4, 915-925

2 Schmidt, C., Bladt, F., Goedecke, S., Brinkmann, V., Zschiesche, W., Sharpe, M., Gherardi, E. and Birchmeier, C. (1995) Scatter factor/hepatocyte growth factor is essential for liver development. Nature 373, 699-702

3 Uehara, Y., Minowa, O., Mori, C., Shiota, K., Kuno, J., Noda, T. and Kitamura, N. (1995) Placental defect and embryonic lethality in mice lacking hepatocyte growth factor/scatter factor. Nature 373, 702-705

4 Chirgadze, D. Y., Hepple, J. P., Zhou, H., Byrd, R. A., Blundell, T. L. and Gherardi, E. (1999) Crystal structure of the NK1 fragment of HGF/SF suggests a novel mode for growth factor dimerization and receptor binding. Nat. Struct. Mol. Biol. 6, 72-79

5 Kirchhofer, D., Yao, X., Peek, M., Eigenbrot, C., Lipari, M. T., Billeci, K. L., Maun, H. R., Moran, P., Santell, L., Wiesmann, C. and Lazarus, R. A. (2004) Structural and functional basis of the serine protease-like hepatocyte growth factor $\beta$-chain in Met binding and signaling. J. Biol. Chem. 279, 39915-39924

6 Gherardi, E., Sandin, S., Petoukhov, M. V., Finch, J., Youles, M. E., Ofverstedt, L. G., Miguel, R. N., Blundell, T. L., Vande Woude, G. F., Skoglund, U. and Svergun, D. I. (2006) Structural basis of hepatocyte growth factor/scatter factor and MET signalling. Proc. Natl. Acad. Sci. U.S.A. 103, 4046-4051

7 Mangel, W. F., Lin, B. H. and Ramakrishnan, V. (1990) Characterization of an extremely large, ligand-induced conformational change in plasminogen. Science 248, 69-73

8 Shimomura, T., Miyazawa, K., Komiyama, Y., Hiraoka, H., Naka, D., Morimoto, Y. and Kitamura, N. (1995) Activation of hepatocyte growth factor by two homologous proteases, blood-coagulation factor XIla and hepatocyte growth factor activator. Eur. J. Biochem. 229, 257-261

9 Itoh, H., Naganuma, S., Takeda, N., Miyata, S., Uchinokura, S., Fukushima, T., Uchiyama, S., Tanaka, H., Nagaike, K. and Shimomura, T. (2004) Regeneration of injured intestinal mucosa is impaired in hepatocyte growth factor activator-deficient mice. Gastroenterology 127, 1423-1435

10 Miyazawa, K., Shimomura, T. and Kitamura, N. (1996) Activation of hepatocyte growth factor in the injured tissues is mediated by hepatocyte growth factor activator. J. Biol. Chem. 271, 3615-3618

11 Qiu, D., Owen, K., Gray, K., Bass, R. and Ellis, V. (2007) Roles and regulation of membrane-associated serine proteases. Biochem. Soc. Trans. 35, 583-587

12 Naldini, L., Tamagnone, L., Vigna, E., Sachs, M., Hartmann, G., Birchmeier, W., Daikuhara, Y., Tsubouchi, H., Blasi, F. and Comoglio, P. M. (1992) Extracellular proteolytic cleavage by urokinase is required for activation of hepatocyte growth factor/scatter factor. EMBO J. 11, 4825-4833 
13 Naldini, L., Vigna, E., Bardelli, A., Follenzi, A., Galimi, F. and Comoglio, P. M. (1995) Biological activation of pro-HGF (hepatocyte growth factor) by urokinase is controlled by a stoichiometric reaction. J. Biol. Chem. 270, 603-611

14 Mars, W. M., Zarnegar, R. and Michalopoulos, G. K. (1993) Activation of hepatocyte growth factor by the plasminogen activators UPA and IPA. Am. J. Pathol. 143, 949-958

15 Mars, W. M., Jo, M. and Gonias, S. L. (2005) Activation of hepatocyte growth factor by urokinase-type plasminogen activator is ionic strength-dependent. Biochem. J. $\mathbf{3 9 0}$, $311-315$

16 Ellis, V., Behrendt, N. and Danø, K. (1991) Plasminogen activation by receptor-bound urokinase: a kinetic study with both cell-associated and isolated receptor. J. Biol. Chem. 266, 12752-12758

17 Mizuno, K., Takehara, T. and Nakamura, T. (1992) Proteolytic activation of a single-chain precursor of hepatocyte growth factor by extracellular serine-protease. Biochem. Biophys. Res. Commun. 189, 1631-1638

18 Matsuoka, H., Sisson, T. H., Nishiuma, T. and Simon, R. H. (2006) Plasminogen-mediated activation and release of hepatocyte growth factor from extracellular matrix. Am. J. Respir. Cell Mol. Biol. 35, 705-713

19 Shanmukhappa, K., Matte, U., Degen, J. L. and Bezerra, J. A. (2009) Plasmin-mediated proteolysis is required for hepatocyte growth factor activation during liver repair. J. Biol. Chem. 284, 12917-12923

20 Lee, S. L., Dickson, R. B. and Lin, C. Y. (2000) Activation of hepatocyte growth factor and urokinase/plasminogen activator by matriptase, an epithelial membrane serine protease. J. Biol. Chem. 275, 36720-36725

21 Herter, S., Piper, D. E., Aaron, W., Gabriele, T., Cutler, G., Cao, P., Bhatt, A. S., Choe, Y., Craik, C. S., Walker, N. et al. (2005) Hepatocyte growth factor is a preferred in vitro substrate for human hepsin, a membrane-anchored serine protease implicated in prostate and ovarian cancers. Biochem. J. 390, 125-136

22 Kirchhofer, D., Peek, M., Lipari, M. T., Billeci, K., Fan, B. and Moran, P. (2005) Hepsin activates pro-hepatocyte growth factor and is inhibited by hepatocyte growth factor activator inhibitor-1B (HAl-1B) and HAl-2. FEBS Lett. 579, 1945-1950

23 Kilpatrick, L. M., Harris, R. L., Owen, K. A., Bass, R., Ghorayeb, C., Bar-Or, A. and Ellis, V. (2006) Initiation of plasminogen activation on the surface of monocytes expressing the type II transmembrane serine protease matriptase. Blood 108, 2616-2623

24 Steinmetzer, T., Schweinitz, A., Sturzebecher, A., Donnecke, D., Uhland, K., Schuster, 0. Steinmetzer, P., Muller, F., Friedrich, R., Than, M. E. et al. (2006) Secondary amides of sulfonylated 3-amidinophenylalanine. New potent and selective inhibitors of matriptase. J. Med. Chem. 49, 4116-4126

25 Riddick, A. C., Shukla, C. J., Pennington, C. J., Bass, R., Nuttall, R. K., Hogan, A., Sethia, K. K., Ellis, V., Collins, A. T., Maitland, N. J. et al. (2005) Identification of degradome components associated with prostate cancer progression by expression analysis of human prostatic tissues. Br. J. Cancer 92, 2171-2180

26 Harris, J. L., Backes, B. J., Leonetti, F., Mahrus, S., Ellman, J. A. and Craik, C. S. (2000) Rapid and general profiling of protease specificity by using combinatorial fluorogenic substrate libraries. Proc. Natl. Acad. Sci. U.S.A. 97, 7754-7759

Received 16 September 2009/26 November 2009; accepted 17 December 2009

Published as BJ Immediate Publication 17 December 2009, doi:10.1042/BJ20091448
27 Marcotte, P. A., Henkin, J., Credo, R. B. and Badylak, S. F. (1992) A-chain isozymes of recombinant and natural urokinases: preparation, characterization, and their biochemical and fibrinolytic properties. Fibrinolysis 6, 69-78

28 Ellis, V., Whawell, S. A., Werner, F. and Deadman, J. J. (1999) Assembly of urokinase receptor-mediated plasminogen activation complexes involves direct, non-active-site interactions between urokinase and plasminogen. Biochemistry 38, 651-659

29 Collen, D., Zamarron, C., Lijnen, H. R. and Hoylaerts, M. (1986) Activation of plasminogen by pro-urokinase. II. Kinetics. J. Biol. Chem. 261, 1259-1266

30 Kemp, L. E., Mulloy, B. and Gherardi, E. (2006) Signalling by HGF/SF and Met: the role of heparan sulphate co-receptors. Biochem. Soc. Trans. 34, 414-417

31 Stephens, R. W., Bokman, A. M., Myohanen, H. T., Reisberg, T., Tapiovaara, H., Pedersen, N., Grøndahl-Hansen, J., Llinas, M. and Vaheri, A. (1992) Heparin binding to the urokinase kringle domain. Biochemistry 31, 7572-7579

32 Takeuchi, T., Harris, J. L., Huang, W., Yan, K. W., Coughlin, S. R. and Craik, C. S. (2000) Cellular localization of membrane-type serine protease 1 and identification of protease-activated receptor-2 and single-chain urokinase-type plasminogen activator as substrates. J. Biol. Chem. 275, 26333-26342

33 Høyer-Hansen, G., Rønne, E., Solberg, H., Behrendt, N., Ploug, M., Lund, L. R., Ellis, V. and Danø, K. (1992) Urokinase plasminogen activator cleaves its cell surface receptor releasing the ligand-binding domain. J. Biol. Chem. 267, 18224-18229

34 Ke, S. H., Coombs, G. S., Tachias, K., Corey, D. R. and Madison, E. L. (1997) Optimal subsite occupancy and design of a selective inhibitor of urokinase. J. Biol. Chem. 272 , 20456-20462

34a Bugge, T. H., Antalis, T. M. and Wu, Q. (2009) Type II transmembrane serine proteases. J. Biol. Chem. 284, 23177-23181

35 Shimizu, M., Hara, A., Okuno, M., Matsuno, H., Okada, K., Ueshima, S., Matsuo, O., Niwa, M., Akita, K., Yamada, Y. et al. (2001) Mechanism of retarded liver regeneration in plasminogen activator-deficient mice: impaired activation of hepatocyte growth factor after Fas-mediated massive hepatic apoptosis. Hepatology 33, 569-576

36 Lamszus, K., Joseph, A., Jin, L., Yao, Y., Chowdhury, S., Fuchs, A., Polverini, P. J., Goldberg, I. D. and Rosen, E. M. (1996) Scatter factor binds to thrombospondin and other extracellular matrix components. Am. J. Pathol. 149, 805-819

37 Rahman, S., Patel, Y., Murray, J., Patel, K. V., Sumathipala, R., Sobel, M. and Wijelath, E. S. (2005) Novel hepatocyte growth factor (HGF) binding domains on fibronectin and vitronectin coordinate a distinct and amplified Met-integrin induced signalling pathway in endothelial cells. BMC Cell Biol. 6, 8

38 Mohammed, F. F., Pennington, C. J., Kassiri, Z., Rubin, J. S., Soloway, P. D., Ruther, U., Edwards, D. R. and Khokha, R. (2005) Metalloproteinase inhibitor TIMP-1 affects hepatocyte cell cycle via HGF activation in murine liver regeneration. Hepatology $\mathbf{4 1}$, $857-867$

39 You, X., Yu, H. M., Cohen-Gould, L., Cao, B., Symons, M., Vande Woude, G. F. and Knudsen, B. S. (2003) Regulation of migration of primary prostate epithelial cells by secreted factors from prostate stromal cells. Exp. Cell Res. 288, 246-256 
online dato

\section{SUPPLEMENTARY ONLINE DATA}

\section{Pericellular activation of hepatocyte growth factor by the transmembrane serine proteases matriptase and hepsin, but not by the membrane-associated protease uPA}

Kate A. OWEN*, Deyi QIU*, Juliano ALVES $\dagger$, Andrew M. SCHUMACHER $\dagger$, Lynette M. KILPATRICK*, Jun LI $\dagger$, Jennifer L. HARRIS $\dagger$ and Vincent ELLIS*1

*Biomedical Research Centre, School of Biological Sciences, University of East Anglia, Norwich NR4 7TJ, U.K., and †Genomics Institute of the Novartis Research Foundation, 10675 John Jay Hopkins Drive, San Diego, CA 92121, U.S.A.

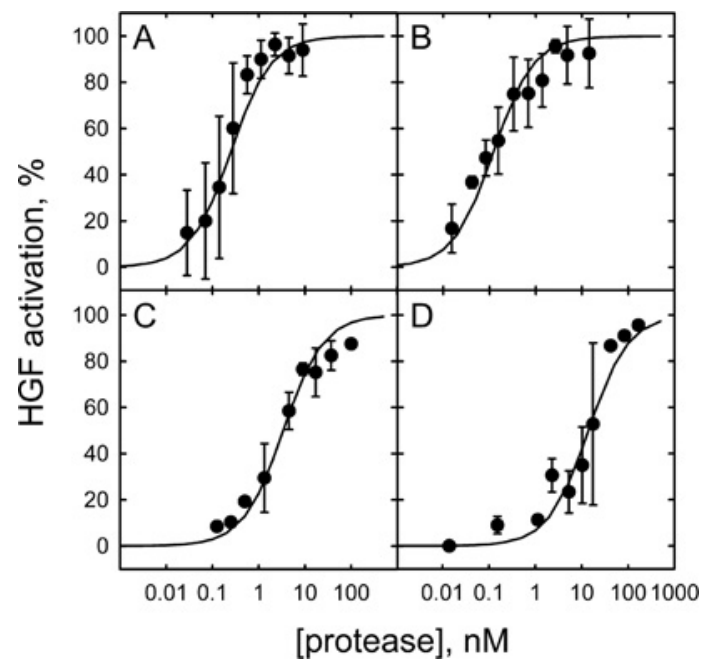

Figure S1 Quantification of pro-HGF activation by serine proteases in solution

Western blots such as those shown in Figures 2 and 3 in the main paper were quantified for both pro-HGF and HGF light-chain by ECL using a Phosphorlmager ${ }^{\circledR}$. Results are represented as the ratio of HGF light-chain to the total HGF detected on the blot and are expressed as a percentage. Results are means + S.D. for a minimum of three data sets. The results were fitted to a four-parameter logistic function by non-linear regression. Results are shown for (A) HGFA, (B) the matriptase catalytic domain, (C) the hepsin extracellular domain and (D) fXIla.

\footnotetext{
1 To whom correspondence should be addressed (email v.ellis@uea.ac.uk).
} 


\section{A. Matriptase}
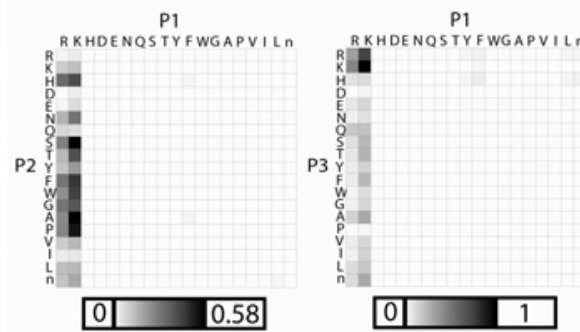

P2

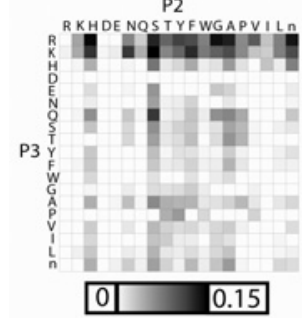

XXOK

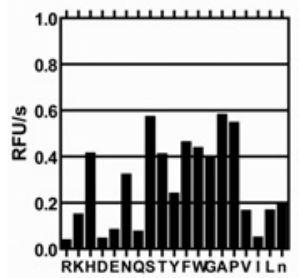

P2

XXOR

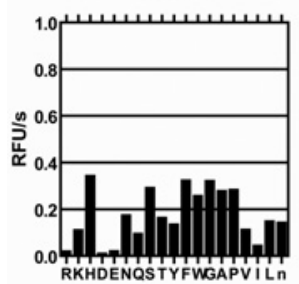

P2

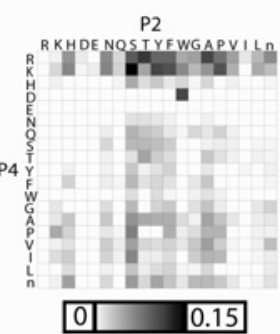

XOXK

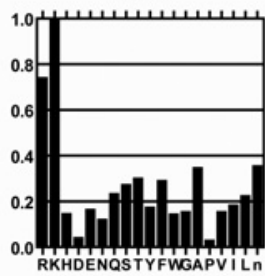

P3

XOXR

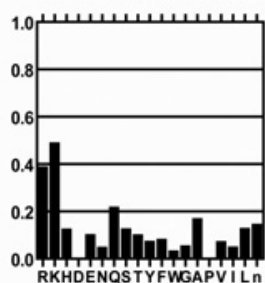

P3
B. Hepsin
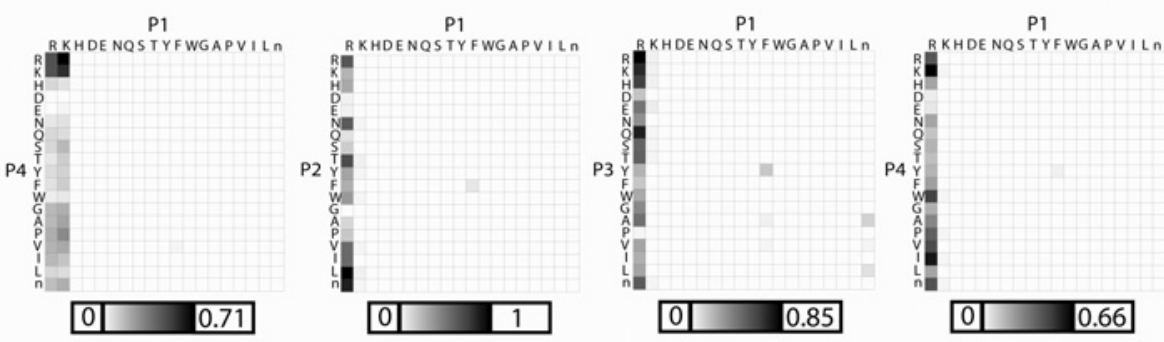

P3
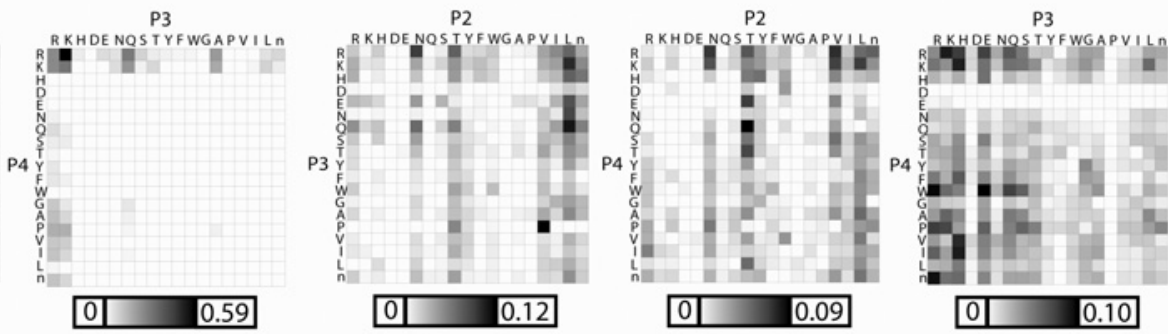

OXXK

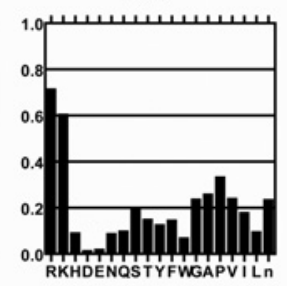

P4

OXXR

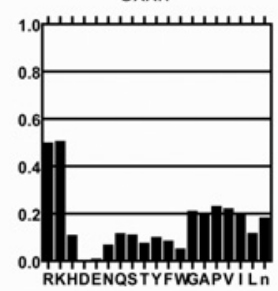

P4
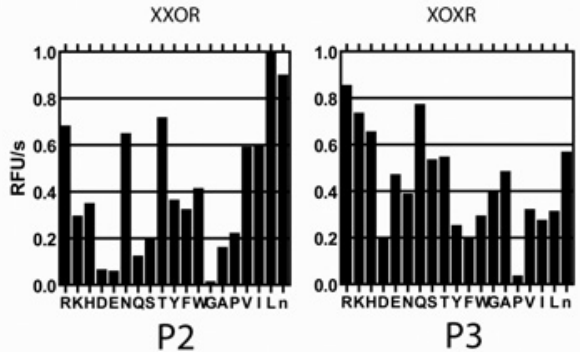

\begin{tabular}{|l|l|}
\hline 0 & 0.10 \\
\hline
\end{tabular}

OXXR

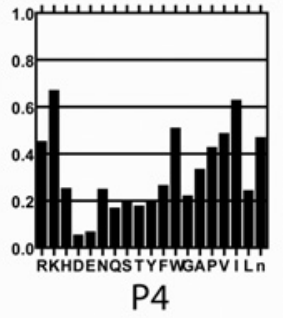

Figure S2 Peptide substrate specificities of matriptase and hepsin in a P4-P1 positional scanning synthetic combinatorial library

(A) Matriptase and (B) hepsin substrate preferences were determined in vitro using peptide substrates in fluorogenic assays as described in the Experimental section in the main paper. The upper two rows of each panel show the initial velocities associated with each substrate in two-position fixed sublibraries, normalized with the highest initial velocity observed, and are presented in a two-dimensional format scaled by grey intensity. The number in the square at the bottom of each sublibrary represents the highest activity in the sublibrary as a proportion of the highest overall activity. The two positions in the substrate that are varied contain an equimolar mixture of 19 amino acids (the mixture excludes cysteine, and methionine is replaced with the isostere norleucine, $\mathrm{n}$ ) for a total of 361 substrates per well. The lower two rows of each panel show the initial velocities of P2, P3 and P4 positions when P1 is fixed (P1 is fixed as an arginine residue for hepsin and P1 is fixed at lysine and arginine for matriptase). $X$ represents the 19-amino acid equimolar mixture (the mixture excludes cysteine, and methionine is replaced with the isostere norleucine, $\mathrm{n}$ ), and 0 represents the single fixed amino acid.

Received 16 September 2009/26 November 2009; accepted 17 December 2009

Published as BJ Immediate Publication 17 December 2009, doi:10.1042/BJ20091448 